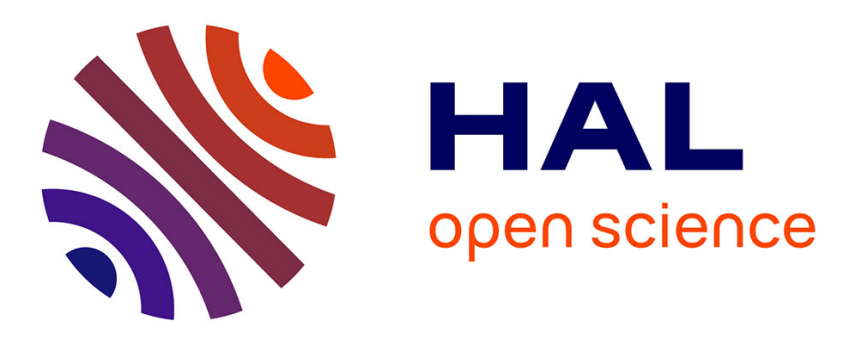

\title{
Sorting out the phytoprostane and phytofuran profile in vegetable oils
}

\author{
Raúl Domínguez-Perles, Ángel Abellán, Daniel León, Federico Ferreres, \\ Alexandre Guy, Camille Oger, Jean Marie Galano, Thierry Durand, Ángel \\ Gil-Izquierdo
}

\section{To cite this version:}

Raúl Domínguez-Perles, Ángel Abellán, Daniel León, Federico Ferreres, Alexandre Guy, et al.. Sorting out the phytoprostane and phytofuran profile in vegetable oils. Food Research International, 2018, 107, pp.619-628. 10.1016/j.foodres.2018.03.013 . hal-02612577

\section{HAL Id: hal-02612577 \\ https://hal.science/hal-02612577}

Submitted on 3 Jun 2021

HAL is a multi-disciplinary open access archive for the deposit and dissemination of scientific research documents, whether they are published or not. The documents may come from teaching and research institutions in France or abroad, or from public or private research centers.
L'archive ouverte pluridisciplinaire HAL, est destinée au dépôt et à la diffusion de documents scientifiques de niveau recherche, publiés ou non, émanant des établissements d'enseignement et de recherche français ou étrangers, des laboratoires publics ou privés. 


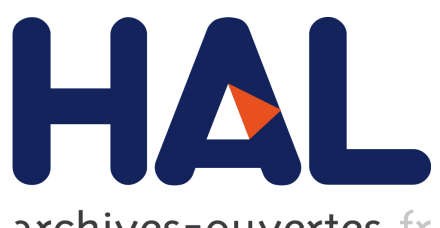

archives-ouvertes

\title{
Sorting out the phytoprostane and phytofuran profile in vegetable oils
}

\author{
Raúl Domínguez-Perles, Ángel Abellán, Daniel León, Federico Ferreres, \\ Alexandre Guy, Camille Oger, Jean Marie Galano, Thierry Durand, Ángel \\ Gil-Izquierdo
}

\section{To cite this version:}

Raúl Domínguez-Perles, Ángel Abellán, Daniel León, Federico Ferreres, Alexandre Guy, et al.. Sorting out the phytoprostane and phytofuran profile in vegetable oils. Food Research International, Elsevier, 2018, 107, pp.619-628. 10.1016/j.foodres.2018.03.013 . hal-02612577

\section{HAL Id: hal-02612577 \\ https://hal.archives-ouvertes.fr/hal-02612577}

Submitted on 3 Jun 2021

HAL is a multi-disciplinary open access archive for the deposit and dissemination of scientific research documents, whether they are published or not. The documents may come from teaching and research institutions in France or abroad, or from public or private research centers.
L'archive ouverte pluridisciplinaire $\mathbf{H A L}$, est destinée au dépôt et à la diffusion de documents scientifiques de niveau recherche, publiés ou non, émanant des établissements d'enseignement et de recherche français ou étrangers, des laboratoires publics ou privés. 


\title{
Sorting out the phytoprostane and phytofuran profile in vegetable oils
}

\author{
Raúl Domínguez-Perles ${ }^{\mathrm{a}}$, Ángel Abellán ${ }^{\mathrm{a}}$, Daniel León ${ }^{\mathrm{a}}$, Federico Ferreres ${ }^{\mathrm{a}}$, Alexander Guy ${ }^{\mathrm{b}}$, \\ Camille Oger $^{\mathrm{b}}$, Jean Marie Galano ${ }^{\mathrm{b}}$, Thierry Durand ${ }^{\mathrm{b}}$, Ángel Gil-Izquierdo ${ }^{\mathrm{a}, *}$ \\ ${ }^{a}$ Research Group on Quality, Safety, and Bioactivity of Plant Foods, Department of Food Science and Technology, CEBAS-CSIC, University Campus of Espinardo, Edif. 25, \\ 30100, Espinardo, Murcia, Spain \\ ${ }^{\mathrm{b}}$ Institut des Biomolécules Max Mousseron (IBMM), UMR 5247, CNRS, Université de Montpellier, ENSCM, Montpellier, France
}

\section{A R T I C L E I N F O}

\section{Keywords:}

Vegetable oils

a-Linolenic acid

Plant oxylipins

Saponification

UHPLC-ESI-QqQ-MS/MS

\begin{abstract}
A B S T R A C T
Phytoprostanes (PhytoPs) and phytofurans (PhytoFs) are prostaglandin-like compounds, contributing to defense signaling and prevention of cellular damage. These plant oxylipins result from autoxidation of $\alpha$-linolenic acid (ALA) and have been proposed as new bioactive compounds due to their structural analogies with isoprostanes (IsoPs) and prostanoids derived from arachidonic acid in mammals, which have demonstrated diverse biological activities. The present work assesses a wide range of vegetable oils - including extra virgin olive oils $(n=7)$ and flax, sesame, argan, safflower seed, grapeseed, and palm oils - for their content of PhytoPs and PhytoFs. Flax oil displayed the highest concentrations, being notable the presence of 9-epi-9- $\mathrm{D}_{1 \mathrm{t}}-\mathrm{PhytoP}, 9-\mathrm{D}_{1 \mathrm{t}}-\mathrm{PhytoP}, 16-\mathrm{B}_{1}$ PhytoP, and 9- $\mathrm{L}_{1}$-PhytoP $\left(7.54,28.09,28.67\right.$, and $19.22 \mu \mathrm{gL}^{-1}$, respectively), which contributed to a total PhytoPs concentration of $119.15 \mu \mathrm{g} \mathrm{mL}^{-1}$, and of ent-16-(RS)-9-epi-ST- $\Delta^{14}-10$-PhytoF $\left(21.46 \mu \mathrm{gL}^{-1}\right)$. Palm and grapeseed oils appeared as the most appropriate negative controls, given the near absence of PhytoPs and PhytoFs (lower than $0.15 \mu \mathrm{g} \mathrm{mL}^{-1}$ ). These data inform on the chance to develop nutritional trials using flax and grapeseed oils as food matrices that would provide practical information to design further assays intended to determine the actual bioavailability/bioactivity in vivo.
\end{abstract}

\section{Introduction}

Phytoprostanes (PhytoPs) are regio- and stereo-isomeric prostaglandin-like compounds found in plants, being products of $\alpha$-linolenic acid (ALA, C18:3 $n-3$ ) autoxidation (Barbosa et al., 2015; Mueller, 2004). To date, two regioisomeric series (16- $\mathrm{G}_{1}-\mathrm{PhytoPs}$ and $9-\mathrm{G}_{1}$ PhytoPs) have been proposed as precursors of the diverse classes of cyclic PhytoPs (Jahn, Galano, \& Durand, 2010). In the last few years, novel non-enzymatic pathways have been described that lead to the synthesis of phytofurans (PhytoFs) - additional oxygenated metabolites of ALA synthesized under higher oxygen partial pressure (Cuyamendous et al., 2015; Fessel, Porter, Moore, \& Sheller, 2002) - so named for their homology with the 3-hydroxy-2,5-disubstituted tetrahydrofuran structures occurring in mammals, derived from arachidonic acid (AA) (isofurans), docosahexaenoic acid (neurofurans), and adrenic acid (dihomo-isofurans) (de la Torre et al., 2015; Roberts \& Fessel, 2004). Both PhytoPs and PhytoFs are constitutively synthesized in plant cells in response to increased levels of reactive oxygen species (ROS), being part of the molecular tools of higher plants involved in defense signaling and in the prevention of cellular damage caused by redox imbalance (Loeffler et al., 2005).

The demonstration of the biological activities of PhytoPs and PhytoFs has been based on in vitro mechanistic studies, whilst addressing the existing gap of information concerning their actual biological activity in vivo requires further experimental support. In this sense, in vivo assays (regarding not only bioactivity but also bioavailability) would provide valuable data on underexplored issues essential to the understanding of the biological relevance of plant oxylipins (PhytoPs and PhytoFs) in mammals after their dietary intake (Barden et al., 2009; Dupuy et al., 2016). Indeed, the lack of information on the actual concentration reached in the diverse cells and tissues at a systemic level constitutes a major constraint to the development of mechanistic studies into a realistic mode of action, due to the use of improper concentrations exceeding those occurring in vivo and chemical forms not matching those present in vivo in cells and tissues.

For the development of nutritional trials, vegetable oils merit

\footnotetext{
Abbreviations: ALA, $\alpha$-linolenic acid; AA, arachidonic acid; BHT, butylated hydroxytoluene; MRM, multiple reaction monitoring; PCA, principal component analysis; PhytoFs, phy-

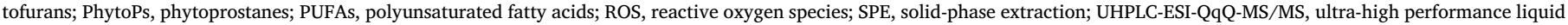
chromatography coupled to electrospray and triple quadrupole mass spectrometry

* Corresponding author at: Research Group on Quality, Safety and Bioactivity of Plant Foods, Department of Food Science and Technology, CEBAS-CSIC, Campus de Espinardo Edif. 25, 30100, Espinardo, Spain.

E-mail address: angelgil@cebas.csic.es (Á. Gil-Izquierdo).
} 
consideration as sources of PhytoPs and PhytoFs given their broad inclusion in the diet in their raw form. In this regard, though a number of scientific articles have addressed the profile and content of PhytoPs in vegetable oils (Collado-González et al., 2015; Collado-González et al., 2015; Karg et al., 2007), the diversity evaluated has not been enough to identify true controls, essential to retrieve consistent results.

The present study profiles and quantifies PhytoPs and PhytoFs in vegetable oils - including extra virgin olive oil (EVOO) from seven distinct varieties of drupes, as well as argan, flax, sesame, grapeseed, safflower, and palm oils. The qualitative and quantitative data were obtained by UHPLC-ESI-QqQ-MS/MS and inform on the best vegetable oil to be included in further bioavailability and clinical trials. The application of biostatistical techniques allowed the determination of both the correlations between individual compounds and the potential of the information obtained for the categorization of the vegetable oils considered.

\section{Materials and methods}

\subsection{Chemical and reagents}

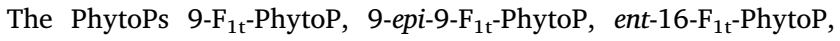
ent-16-epi-16- $\mathrm{F}_{1 \mathrm{t}}-\mathrm{PhytoP}, \quad 9-\mathrm{D}_{1 \mathrm{t}}-\mathrm{PhytoP}, \quad 9-$ epi-9- $\mathrm{D}_{1 \mathrm{t}}-\mathrm{PhytoP}, \quad 16-\mathrm{B}_{1}$ PhytoP, and 9- $\mathrm{L}_{1}$-PhytoP and the PhytoFs ent-16-(RS)-9-epi-ST- $\Delta^{14}-10-$ PhytoF, ent-9-(RS)-12-epi-ST- $\Delta^{10}$-13-PhytoF, and ent-16-(RS)-13-epi-ST$\Delta^{14}$-9-PhytoF (Fig. 1) were synthesized according to procedures described in the literature (Cuyamendous et al., 2015; Cuyamendous et al., 2017; El Fangour et al., 2004; El Fangour, Guy, Vidal, Rossi, \& Durand, 2005; Guy, Flanagan, Durand, Oger, \& Galano, 2015; Oger,
Brinkmann, Bouazzaoui, Durand, \& Galano, 2008; Pinot et al., 2008). They were provided by the Institut des Biomolécules Max Mousseron (IBMM) (Montpellier, France). Hexane and chloroform were obtained from Panreac (Castellar del Vallès, Barcelona, Spain), Bis-Tris (bis(2hydroxyethyl)amino-tris (hydroxymethyl)methane) was purchased from Sigma-Aldrich (St. Louis, MO, USA), and all LC-MS grade solvents, methanol, and acetonitrile were from J.T. Baker (Phillipsburg, NJ, USA). The Strata solid-phase extraction (SPE) cartridges used (Strata $\mathrm{x}-\mathrm{AW}, 100 \mathrm{mg} 3 \mathrm{~mL}^{-1}$ ) were acquired from Phenomenex (Torrance, CA, USA).

\subsection{Vegetable oil samples: preparation and extraction}

The samples consisted of the commercial oils: $0.1^{\circ}$ extra virgin olive (Olea europaea L.) oils made using the drupe varieties 'Arbequina', 'Coupage', 'Koroneiki', 'Cuquillo', 'Hojiblanca', 'Cornicabra', and 'Picual' (Oilmedros S.L., Jumilla, Spain), and bio-organic virgin flax (Linum usitatissimum L.), virgin sesame (Sesamum indicum L.), and virgin argan (Argania spinosa L.) oils (Laboratorios Almond, NaturGreen, Librilla, Spain). In addition, safflower (Carthamus tinctorious L.) seed (Nutrition \& Santé Ibérica SL, Sant Cugat del Vallès, Spain), grapeseed (Vitis vinifera L.) (La compagnie des saveurs, Novers-Sur-Cher, France), and palm (Elaeis guineensis) (Gracomsa alimentaria S.A., Valencia, Spain) oils were also assessed for their content of PhytoPs and PhytoFs. The oils were stored at room temperature (RT), protected from light, until extraction and analysis.

The PhytoPs and PhytoFs present in the oils were extracted following the methodology described by Leung, Chen, Zhong, Yu, and Lee (2014) and Yonny et al. (2015), with minor modifications for its
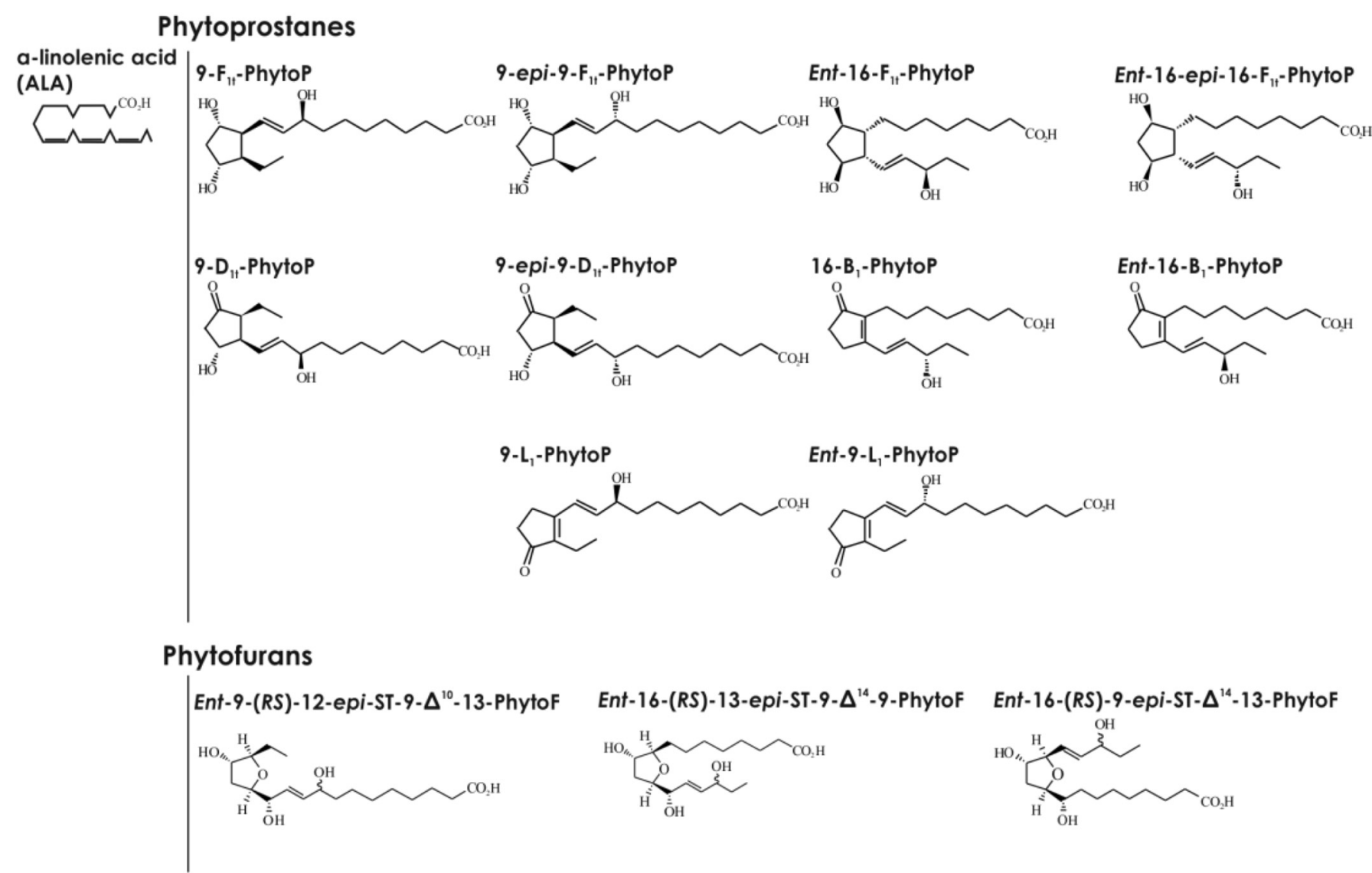

\section{Ent-16-(RS)-13-epi-ST-9- $\Delta^{14}$-9-PhytoF}

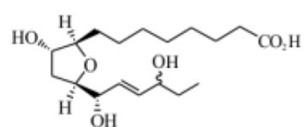

Ent-16-(RS)-9-epi-ST- $\Delta^{14}$-13-PhytoF<smiles>CC[C@H](O)/C=C/[C@H]1O[C@H](O)C[C@H]1O</smiles>

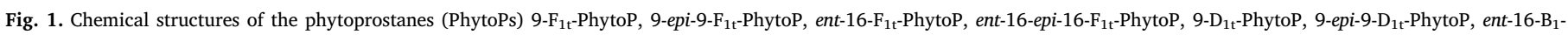

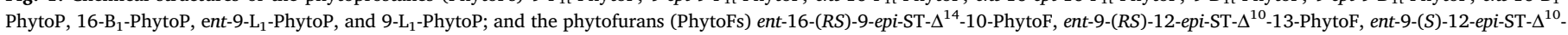

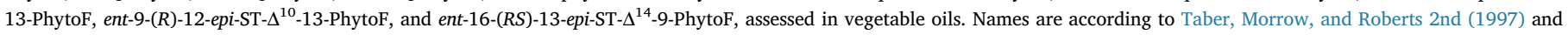
Cuyamendous et al. (2016). 
adaptation to liquid samples. Briefly, each vegetable oil $(1.0 \mathrm{~mL})$ was mixed with $8.0 \mathrm{~mL}$ of $0.1 \%$ butylated hydroxytoluene (BHT) in methanol (w/v), and the mixture was stirred at $200 \mathrm{rpm}$ for $10 \mathrm{~min}$ in an orbital shaker. Afterwards, $4.0 \mathrm{~mL}$ of chloroform and $1.0 \mathrm{~mL}$ of milliQwater were added and the mixture was stirred at $200 \mathrm{rpm}$ for $15 \mathrm{~min}$, at $\mathrm{RT}$, in an orbital shaker before being centrifuged at $1800 \mathrm{~g}$, for $10 \mathrm{~min}$ at $4{ }^{\circ} \mathrm{C}$. The chloroform phase was separated and dried using a SpeedVac concentrator (Savant SPD121P, Thermo Scientific, MA, USA). The dry residue was suspended in $2.0 \mathrm{~mL}$ of hexane and $2.0 \mathrm{~mL}$ of $0.02 \mathrm{M}$ BisTris (pH 7) and kept at $4{ }^{\circ} \mathrm{C}$ until further clean-up by SPE.

The SPE clean-up of the extracts was developed using Strata X-AW cartridges

(100 mg $\left.3.0 \mathrm{~mL}^{-1}\right)$, according to the procedure described previously (Collado-González, Medina, et al., 2015; Medina et al., 2012). To reveal the recovery of each analyte, the ratio "(final concentration - initial concentration) / initial concentration" was determined for three different concentrations within the previously estimated linear range for the separate standards $\left(68.89,137.78\right.$, and $\left.215.28 \mathrm{ng} \mathrm{mL}^{-1}\right)$. The target compounds were eluted with $1.0 \mathrm{~mL}$ of methanol and dried using a SpeedVac concentrator. The dry extracts were reconstituted with $200 \mu \mathrm{L}$ of milliQ-water/MeOH (50:50, v/v), sonicated for $10 \mathrm{~min}$, and filtered through a $0.45-\mu \mathrm{m}$ filter (Millipore, MA, USA). The recovery was calculated in quintuplicate $(n=5)$ for each concentration.

\subsection{UHPL-ESI-QqQ-MS/MS analysis of phytoprostanes and phytofurans}

Chromatographic separation of PhytoPs and PhytoFs was performed using a UHPLC coupled with a 6460 triple quadrupole-MS/MS (Agilent Technologies, Waldbronn, Germany) according to the methodology described by Collado-González, Medina, et al. (2015), with the inclusion of three additional compounds, which validation is presented in the present work. The analytical column was a BEH C18 $(2.1 \times 50 \mathrm{~mm}$, $1.7 \mu \mathrm{m}$ ) (Waters, Milford, MA). The column temperatures were both $6{ }^{\circ} \mathrm{C}$ (left and right). The mobile phases consisted of milliQ-water/acetic acid (99.99:0.01, v/v) (A) and methanol/acetic acid (99.99:0.01, v/v) (B). The sample injection volume and flow rate were $20 \mu \mathrm{L}$ and $0.2 \mathrm{~mL} \mathrm{~min}^{-1}$, respectively. The chromatographic separation was achieved through the following linear gradient (time (min), \%B): $(0.00$, $60.0 \%)$; $(2.00,62.0 \%)$; $(4.00,62.5 \%)$; $(8.00,65.0 \%)$; and $(8.01$, $60.0 \%$ ). An additional post-run of $1.5 \mathrm{~min}$ was used for column equilibration. The MS analysis was conducted by multiple reaction monitoring (MRM) operated in the negative mode, assigning preferential MRM transition to the corresponding analytes (Table 1). The operating conditions regarding the MS parameters were: gas temperature: $325^{\circ} \mathrm{C}$, gas flow: $8 \mathrm{~L} \mathrm{~min}^{-1}$, nebulizer: $30 \mathrm{psi}$, sheath gas temperature: $350^{\circ} \mathrm{C}$, jet-stream gas flow: $12 \mathrm{~L} \mathrm{~min}^{-1}$, capillary voltage: $3000 \mathrm{~V}$, and nozzle voltage: $1750 \mathrm{~V}$. Data acquisition and processing were performed using MassHunter software version B.04.00 (Agilent Technologies).

\subsection{Sensitivity, precision, and accuracy}

The sensitivity of the analytical method (referred to the three PhytoFs ent-16-(RS)-9-epi-ST- $\Delta^{14}-10-P h y t o F$, ent-9-(RS)-12-epi-ST- $\Delta^{10}$ 13-PhytoF, and ent-16-(RS)-13-epi-ST- $\Delta^{14}$-9-PhytoF, which were added to the method developed and validated by Collado-González, Medina, et al. (2015)) was evaluated as the limits of detection (LOD) and quantification (LOQ), as the lowest concentration of an analyte that can be detected but not necessarily quantified and quantified, respectively. In our method, the LOD and LOQ were established with an $\mathrm{S} / \mathrm{N}$ ratio of 3:1 and 10:1, respectively (International Conference on Harmonization (ICH), 1994).

The precision (coefficient of variation (CV\%)) and the accuracy (\% deviation) of the intra- and inter-day assays were evaluated for three concentrations (three replicates per concentration) of these PhytoFs $\left(68.89,137.78\right.$, and $\left.215.28 \mathrm{ng} \mathrm{mL}^{-1}\right)$ by carrying out two runs per day on five independent days. The concentrations were determined with daily calibration curves. The precision was calculated as " $\mathrm{CV}$ $\%=($ standard deviation $/$ mean $) \times 100$ ", whilst the standard deviation informed on the accuracy of the method (FDA, US Department of Health and Human Services, 2001).

\subsection{Statistical analyses}

All extractions were performed in triplicate $(n=3)$ and the data were expressed as the means and the least significant differences (LSD). All statistical tests were performed at a 5\% significance level using the SPSS 22.0 software package (LEAD Technologies, Inc., Chicago, USA). All the data were subjected to one-way analysis of variance (ANOVA). The fulfillment of the one-way ANOVA requirements, specifically the normal distribution of the residuals and the homogeneity of variance, was tested by the Kolmogorov-Smirnov (with Lilliefors correction) and Levene test, respectively. When statistical differences were identified, the variables were compared using Tukey's multiple range test.

Principal component analysis (PCA) was applied as a pattern recognition unsupervised classification method. The number of dimensions kept for data analysis was evaluated by the respective eigenvalues (which should be higher than one), using the total percentage of variance. The number of plotted dimensions was chosen in order to allow meaningful interpretations, thereby ensuring their reliability. Pearson's correlation was conducted and significant correlations were set at $p<0.05$.

\section{Results \& discussion}

The measurement of PhytoPs and PhytoFs was developed in a suite of vegetable oils, using a newly validated UHPLC-ESI-QqQ-MS/MS method for PhytoFs that is specific, sensitive, reproducible, and robust as well as representing an updated method for PhytoPs, relative to the one previously described by Collado-González, Medina, et al. (2015) that is complemented by including three new analytes (ent-16-(RS)-9epi-ST- $\Delta^{14}-10-$ PhytoF, ent-9-(RS)-12-epi-ST- $\Delta^{10}-13$-PhytoF, and ent-16(RS)-13-epi-ST- $\left.\Delta^{14}-9-\mathrm{PhytoF}\right)$. Hence, the cross-reactivity between the diverse plant oxylipins is resolved by the method applied in the present work, which provides a clear separation and identification of enantiomers and reduces interferences between compounds. For identification and quantification purposes, two transitions were used for each separate compound: the more intense one for quantification and the additional MRM transition for confirmation of the identity of the compound (Table 1). Indeed, the use of two pairs of MRM transition is recommended by the European Commission (Commission Decision2002/657/EC, 2002) and the International Conference on Harmonization (International Conference on Harmonization (ICH, 1994). These publications noticed the very valuable confirmation of the LC-MS results provided by mass spectral fragmentation and the ability to filter out by mass any impurities interfering in spectrophotometric detectors. In this regard, working in Multiple Reaction Monitoring mode allows to monitor two (or more) transition for each analyte, being used the first one for the quantification of the target compound, whilst the second product ion is monitored for the confirmation of the compound identity. In addition, the compounds under evaluation also showed distinct retention times that guaranteed their identification without any constraint (Table 1).

\subsection{Qualitative and quantitative MRM transitions, and analytical selectivity}

Because of the occurrence of a free carboxylic group in PhytoPs and PhytoFs, the negative ESI mode gives a more efficient ionization and thus a more proficient detection and quantification of plant oxylipins (Medina et al., 2012). Besides, complementary MRM transitions (qualitative transitions) were included in the method for further confirmation of the identity of the compounds (Table 1). Hence, the analytical 
Table 1

UHPLC/MS/MS parameters for the quantification and confirmation of phytoprostanes and phytofurans in vegetable oils.

\begin{tabular}{|c|c|c|c|c|c|}
\hline Compound & Retention time (min) & ESI mode & MRM transition $(m / z)$ & Fragmentor (V) & Collision energy (V) \\
\hline \multicolumn{6}{|l|}{ Phytoprostanes } \\
\hline \multirow[t]{2}{*}{ Ent-16-epi-16- $\mathrm{F}_{1 \mathrm{t}}-\mathrm{Phyto}^{\mathrm{X}}$} & 1.583 & Negative & $327.1>283.2^{Z}$ & 80 & 15 \\
\hline & & Negative & $327.1>225.1^{\mathrm{Y}}$ & 80 & 15 \\
\hline \multirow[t]{2}{*}{ 9-F $\mathrm{F}_{1 \mathrm{t}}-\mathrm{PhytoP}$} & 1.631 & Negative & $327.2>273.1$ & 110 & 15 \\
\hline & & Negative & $327.2>171.0$ & 110 & 15 \\
\hline \multirow{2}{*}{ Ent-16- $\mathrm{F}_{1 \mathrm{t}}-\mathrm{PhytoP}^{\mathrm{X}}$} & 1.712 & Negative & $327.2>283.2$ & 80 & 10 \\
\hline & & Negative & $327.2>225.1$ & 80 & 10 \\
\hline \multirow[t]{2}{*}{ 9-epi-9- $\mathrm{F}_{1 \mathrm{t}}$-PhytoP } & 1.785 & Negative & $327.2>272.8$ & 110 & 10 \\
\hline & & Negative & $327.2>171.0$ & 110 & 10 \\
\hline \multirow[t]{2}{*}{ 9- $\mathrm{D}_{1 \mathrm{t}}$-PhytoP } & 1.791 & Negative & $325.2>307.3$ & 100 & 4 \\
\hline & & Negative & $325.2>134.7$ & 100 & 4 \\
\hline \multirow[t]{2}{*}{ 9-epi-9-D ${ }_{1 \mathrm{t}}$-PhytoP } & 2.022 & Negative & $325.2>307.2$ & 100 & 7 \\
\hline & & Negative & $325.2>134.9$ & 100 & 7 \\
\hline \multirow[t]{2}{*}{ 16-B-BhytoP } & 2.620 & Negative & $3.7 .2>223.2$ & 100 & 10 \\
\hline & & Negative & $307.2>235.1$ & 100 & 100 \\
\hline \multirow[t]{2}{*}{ 9- $\mathrm{L}_{1}-$ PhytoP } & 3.079 & Negative & $307.2>185.1$ & 110 & 7 \\
\hline & & Negative & $307.2>196.7$ & 110 & 7 \\
\hline \multicolumn{6}{|l|}{ Phytofurans } \\
\hline \multirow[t]{2}{*}{ Ent-9-(RS)-12-epi-ST- $\Delta^{10}{ }^{13}-$-PhytoF } & 0.906 & Negative & $344.0>300.0$ & 110 & 10 \\
\hline & & Negative & $344.0>255.9$ & 110 & 10 \\
\hline \multirow[t]{2}{*}{ Ent-16-(RS)-9-epi-ST- $\Delta^{14}-10$-PhytoF } & 1.501 & Negative & $343.9>209.0$ & 90 & 12 \\
\hline & & Negative & $343.9>201.1$ & 90 & 12 \\
\hline \multirow[t]{2}{*}{ Ent-16-(RS)-13-epi-ST- $\Delta^{14}$-9-PhytoF } & 1.523 & Negative & $343.0>171.1$ & 90 & 22 \\
\hline & & Negative & $343.0>97.2$ & 90 & 22 \\
\hline
\end{tabular}

\footnotetext{
${ }^{\mathrm{z}}$ Quantification transition.

${ }^{Y}$ Confirmation transition.

${ }^{\mathrm{x}}$ Coeluting diastereoisomers quantified together.
}

selectivity of the method used allowed the differentiation of specific analytes eluting at matching retention times from other matrix components with similar chemical features.

\subsection{Calibration curves}

The quantification of the PhytoPs and PhytoFs involved the daily preparation of calibration curves using standard solutions. The linearity was assessed using milli-Q-water/methanol (50:50, v/v) solutions of the standards. The calibration curves were fitted using linear regression equations of the type " $y=a x+b$ "; the correlation coefficients $\left(\mathrm{R}^{2}\right)$ were higher than 0.99 within the concentration range of 10.34 to $344.44 \mathrm{ng} \mathrm{mL}^{-1}$, thus showing the adequate linearity of the analytical procedure. The standard curves were prepared separately for each compound or with a pool of all the standards, with identical satisfactory results.

\subsection{Recovery, sensitivity, precision, and accuracy}

When samples are cleaned-up by SPE, it is mandatory to evaluate the recovery of the compounds of interest. In addition to the selectivity of the SPE cartridges, the recovery may be affected by several other factors, including chromatography and ionization at the source. In addition, since the matrix-related ion-suppression effect that features in the MS analyses of these compounds, limits dramatically the detection and quantification capacity for some PhytoPs and PhytoFs, recovery tests are mandatory. The Strata X-AW cartridge used for the SPE gave an elevated recovery and good reproducibility (Table 2 ) for all three PhytoFs $\quad\left(86.5-108.1 \%\right.$ for ent-9-(RS)-12-epi-ST- $\Delta^{10}-13-$ PhytoF; $108.9-121.5 \%$ for ent-16-(RS)-9-epi-ST- $\Delta^{14}-10-$ PhytoF; and 96.8-123.0\% for ent-16-(RS)-13-epi-ST- $\Delta^{14}-9-$ PhytoF) due to the weak ionic-exchange interaction of its resin.

The LOD and LOQ of the compounds analyzed were, respectively, 4.45 and $14.88 \mathrm{ng} \mathrm{mL}^{-1}$ for ent-9-(RS)-12-epi-ST- $\Delta^{10}$-13-PhytoF, 2.02 and $6.73 \mathrm{ng} \mathrm{mL}^{-1}$ for ent-16-(RS)-9-epi-ST- $\Delta^{14}-10$-PhytoF, and 0.10 and $0.34 \mathrm{ng} \mathrm{mL}^{-1}$ for ent-16-(RS)-13-epi-ST- $\Delta^{14}-9$-PhytoF (Table 3). The intra- and inter-day CV\% or precision and the percentage of variation or
Table 2

Recovery of PhytoFs.

\begin{tabular}{lll}
\hline Analyte & Added $\left(\mathrm{ng} \mathrm{mL}^{-1}\right)$ & Absolute recovery (\%) \\
\hline Ent-9-(RS)-12-epi-ST- ${ }^{10}{ }^{-13-P h y t o F}$ & 68.89 & $86.48 \pm 4.1$ \\
& 137.78 & $108.05 \pm 19.4$ \\
& 215.28 & $102.71 \pm 5.0$ \\
Ent-16-(RS)-9-epi-ST- $\Delta^{14}$-10-PhytoF & 68.89 & $108.93 \pm 22.0$ \\
& 137.78 & $121.48 \pm 12.1$ \\
Ent-16-(RS)-13-epi-ST- $\Delta^{14}$-9-PhytoF & 215.28 & $112.66 \pm 11.9$ \\
& 68.89 & $104.42 \pm 18.0$ \\
& 137.78 & $96.79 \pm 12.1$ \\
& 215.28 & $122.96 \pm 10.5$ \\
\hline
\end{tabular}

accuracy were within the acceptable limit $(<15 \%)$ set up by the International Conference of Harmonization (ICH, 1994). Actually, the CV $\%$ ranged from 2.9 to $13.3 \%$ and from 3.1 to $12.7 \%$ for the intra- and inter-day multiple determinations, respectively. The accuracies retrieved varied between 85.6 and $103.4 \%$ (intra-day) and between 83.0 and $110.5 \%$ (inter-day) (Table 4).

\subsection{Phytoprostanes and phytofurans profiles in vegetable oils}

The assessment of the vegetable oils studied in the present work, regarding their profiles of PhytoPs and PhytoFs, provided accurate information on the compounds present in each matrix and their abundance. The synthesis of PhytoPs and PhytoFs by higher plants is closely dependent on the presence of ALA and molecular oxygen. They are nonenzymatically synthesized and, although these processes do not require metabolic activity of living cells, the formation of ROS in cells (that is related to enzymatic pathways) could play a role in the formation of plant oxylipins (Carrasco-Del Amor et al., 2016; Carrasco-Del Amor et al., 2017; Collado-González et al., 2015; Loeffler et al., 2005). In this regard, since these compounds are end products of the non-enzymatic peroxidation of ALA, their occurrence is strongly conditioned by the features of the processing procedure and the storage conditions, especially in those products obtained from manufacturing processes requiring the breakdown of the food matrix and thus exposure to high 
Table 3

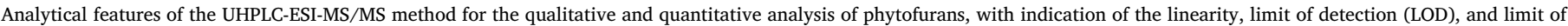
quantification (LOQ) for each compound.

\begin{tabular}{|c|c|c|c|c|}
\hline Analyte & Calibration equation & Coefficient of regression & LOD (ng mL $\left.{ }^{-1}\right)$ & LOQ (ng mL ${ }^{-1}$ ) \\
\hline Ent-9-(RS)-12-epi-ST- $\Delta^{10}-13-P h y t o F$ & $y=101,515.36 x+1733.98$ & 0.9926 & 4.45 & 14.88 \\
\hline Ent-16-(RS)-9-epi-ST- $\Delta^{14}-10-$ PhytoF & $y=54,259.90 x+2055.64$ & 0.9988 & 2.02 & 6.73 \\
\hline Ent-16-(RS)-13-epi-ST- $\Delta^{14}-9-\mathrm{PhytoF}$ & $y=73,044.36 x+1974.49$ & 0.9985 & 0.10 & 0.34 \\
\hline
\end{tabular}

oxygen pressure (Thoma et al., 2003).

The individual compounds present in the vegetable oils analyzed were identified through the use of their mass spectra - considering their pseudomolecular ion $(\mathrm{m} / \mathrm{z})$, the most specific fragmentations, and the elution order represented by the retention times (Table 1 and Fig. 1) according to the method developed by Collado-González, Medina, et al. (2015) and with the use of authentic standards. The number of compounds (PhytoPs and PhytoFs) found decreased as follows: flax oil (11) $>$ safflower oil (7) > EVOO (6) > sesame and argan seed oil (5) $>$ grapeseed and palm oils (4).

These PhytoP and PhytoF profiles should be carefully interpreted since the method applied does not allow the resolution of two mixtures of enantiomers - 16- $\mathrm{B}_{1}-\mathrm{PhytoP}+$ ent-16- $\mathrm{B}_{1}-\mathrm{PhytoP}$, and 9- $\mathrm{L}_{1}$ PhytoP + ent-9- $\mathrm{L}_{1}$-PhytoP - which co-elute, displaying also matching fragmentation patterns that necessitate the use of chiral additives and/ or columns for their proper resolution Collado-González, Medina, et al. (2015). Hence, in the present work these two pairs of PhytoPs were quantified as $16-\mathrm{B}_{1}$-PhytoP and $9-\mathrm{L}_{1}$-PhytoP, respectively. Besides, the chromatographic method applied in the present work was not able to separate the two C-16 epimers of the 16-series of $\mathrm{F}_{1 \mathrm{t}}$-PhytoPs (ent-16epi-16- $\mathrm{F}_{1 \mathrm{t}}$-PhytoP and ent-16- $\left.\mathrm{F}_{1 \mathrm{t}}-\mathrm{PhytoP}\right)$.

The PhytoP profile found in the seven classes of EVOO $\left(0.1^{\circ}\right)$ differed from that recorded in olive oils by Collado-González et al., who reported the presence of ent-16-epi-16- $\mathrm{F}_{1 \mathrm{t}}-\mathrm{PhytoP}$, ent-16- $\mathrm{F}_{1 \mathrm{t}}$-PhytoP, 9epi-9- $\mathrm{D}_{1 \mathrm{t}}$-PhytoP, 9- $\mathrm{D}_{1 \mathrm{t}}$-PhytoP, and 16- $\mathrm{B}_{1}$-PhytoP Collado-González, Medina, et al. (2015). In the current work their presence in EVOO was not observed, except for $16-\mathrm{B}_{1}-\mathrm{PhytoP}$, whereas $9-\mathrm{F}_{1 \mathrm{t}}$-PhytoP and $9-\mathrm{L}_{1}$ PhytoP were found. Diverse factors may be responsible for these apparently contradictory results, particularly the genetic information carried by the separate varieties of olive drupes used to obtain the analyzed oils; this entails distinct concentrations of ALA that could affect the synthesis of PhytoPs and PhytoFs (Imbusch \& Mueller, 2000a). The occurrence of individual PhytoPs in the other vegetable oils evaluated was restricted to $9-\mathrm{F}_{1 \mathrm{t}}$-PhytoP (argan, sesame, grapeseed, and safflower oils), ent-16-epi- $\mathrm{F}_{1 \mathrm{t}}$-PhytoP and ent-16- $\mathrm{F}_{1 \mathrm{t}}$-PhytoP (sesame and safflower oils), 9-epi- $\mathrm{F}_{1 \mathrm{t}}$-PhytoP (argan and grapeseed oils), 9- $\mathrm{L}_{1}$ PhytoP (argan, sesame, safflower, and palm oils), and 16- $\mathrm{B}_{1}$-PhytoP (all of them).

With respect to the occurrence of PhytoFs in vegetable oils, to the best of our knowledge, the data available are restricted to flax oil (Cuyamendous et al., 2017). In this regard, determination of the concentrations of PhytoFs in plant foods is essential to complete our knowledge of the occurrence of plant oxylipins; this shows the need for further evaluation of the bioavailability of such compounds. Within the family of PhytoFs, three different regioisomers were analyzed; ent-16(RS)-9-epi-ST- $\Delta^{14}-10$-PhytoF, ent-9-(RS)-12-epi-ST- $\Delta^{10}-13-P h y t o F$, and ent-16-(RS)-13-epi-ST- $\Delta^{14}-9$-PhytoF. All three were observed in the seven varieties of EVOO and in flax oil. In contrast, ent-16-(RS)-9-epiST- $\Delta^{14}$-9-PhytoF was present in argan, sesame, grapeseed, safflower, and palm oils, whilst ent-9-(RS)-12-epi-ST- $\Delta^{10}-13-$ PhytoF was only detected in grapeseed and palm oils and ent-16-(RS)-13-epi-ST- $\Delta^{14}-9-$ PhytoF in none of these vegetable oils. Again, as for the PhytoPs, the diversity of the PhytoFs profiles recorded in the array of vegetable oils assessed seems to be closely related to differences in the genetic backgrounds, as well as to specific features of the production process (Karg et al., 2007; Collado-González, Medina, et al., 2015.

The wide range of PhytoPs and PhytoFs identified in these vegetable oils reinforces the value of this food matrix for testing their bioavailability and biological activity in vivo, to demonstrate the potential bioactivity of this family of compounds, mainly supported so far by structural analogies with eicosanoids to which have been attributed several powerful biological actions (Barden et al., 2011). This could be demonstrated by the provision of complementary information on their occurrence in vivo after the oral intake of dietary sources and their capacity to modulate the level of expression of biological markers associated with pathophysiological situations in in vitro mechanistic studies. In this regard, given these structural coincidences, it has been suggested that PhytoPs and PhytoFs could develop their biological activity through equal molecular pathways, whilst the chemical diversity of the individual compounds could allow variable mechanisms of action and biological properties.

\subsection{Quantitative occurrence of phytoprostanes and phytofurans in vegetable oils}

Given the high concentration of ALA in vegetable oils used around the world, at the domestic level or in industrial processes (mainly in the baking industry), consumers ingest significant amounts of PhytoPs and PhytoFs, which reach the intestinal tract and are susceptible to absorption and spread at the systemic level (Karg et al., 2007), where they could develop their biological activity. However, to date, there is limited information on the distribution or accumulation of PhytoPs and

Table 4

Intra-day and inter-day coefficients of variation for the determination of PhytoFs.

\begin{tabular}{|c|c|c|c|c|c|c|c|}
\hline \multirow[t]{2}{*}{ Analyte } & \multirow[t]{2}{*}{ Nominal conc. (ng mL ${ }^{-1}$ ) } & \multicolumn{3}{|l|}{ Intra-day } & \multicolumn{3}{|l|}{ Inter-day } \\
\hline & & Measured & RSD (\%) & Accuracy (\%) & Measured & RSD (\%) & Accuracy (\%) \\
\hline \multirow[t]{3}{*}{ Ent-9-(RS)-12-epi-ST- $\Delta^{10}$-13-PhytoF } & 68.89 & $24.72 \pm 1.53$ & 13.3 & 85.6 & $23.98 \pm 2.10$ & 11.2 & 83.0 \\
\hline & 137.78 & $125.65 \pm 2.07$ & 10.7 & 91.2 & $124.89 \pm 2.10$ & 8.9 & 90.6 \\
\hline & 275.55 & $264.35 \pm 23.83$ & 6.0 & 95.9 & $264.12 \pm 19.28$ & 7.2 & 96.1 \\
\hline \multirow[t]{3}{*}{ Ent-16-(RS)-9-epi-ST- $\Delta^{14}-10-P h y t o F$} & 68.89 & $26.12 \pm 1.07$ & 10.1 & 90.4 & $25.96 \pm 0.49$ & 12.7 & 89.9 \\
\hline & 137.78 & $142.45 \pm 1.94$ & 7.7 & 103.4 & $144.12 \pm 2.92$ & 7.7 & 104.6 \\
\hline & 275.55 & $279.65 \pm 12.97$ & 10.6 & 101.5 & $289.89 \pm 15.00$ & 11.8 & 105.2 \\
\hline \multirow[t]{3}{*}{ Ent-16-(RS)-13-epi-ST- $\Delta^{14}$-9-PhytoF } & 68.89 & $27.89 \pm 0.11$ & 5.4 & 96.5 & $27.56 \pm 0.25$ & 7.4 & 95.4 \\
\hline & 137.78 & $140.75 \pm 8.94$ & 2.9 & 102.2 & $152.21 \pm 2.17$ & 3.1 & 110.5 \\
\hline & 275.55 & $283.98 \pm 6.67$ & 4.0 & 103.1 & $292.65 \pm 6.82$ & 4.9 & 106.2 \\
\hline
\end{tabular}




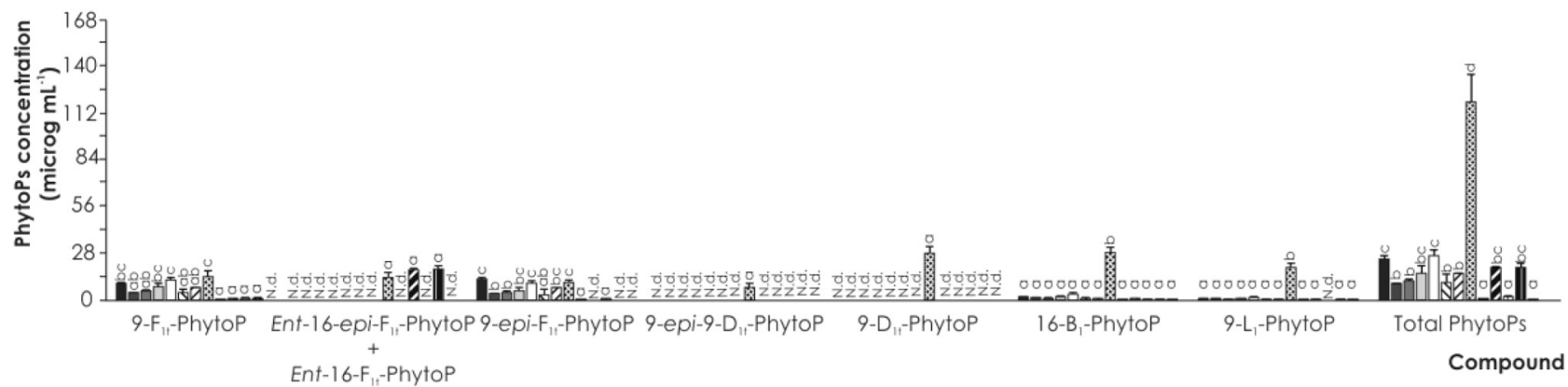

$\square$ Extra virgin olive oil, var. 'Cuquillo'
$\square$ Extra virgin olive oil, var. 'Hojiblanca'
$\square$ Extra virgin olive oil, var. 'coupage'
$\square$ Sesame seed oil
$\boxplus$ Palm oil
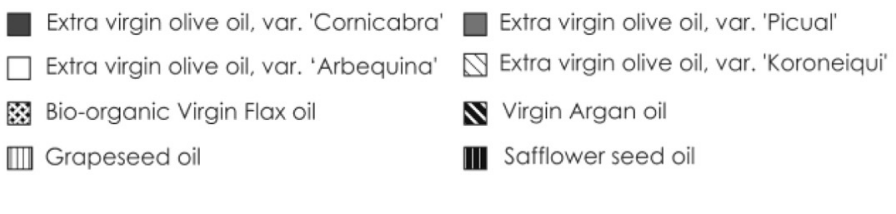

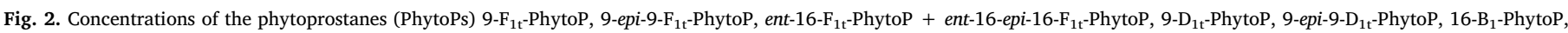

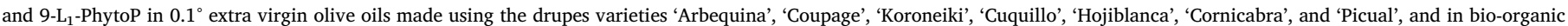

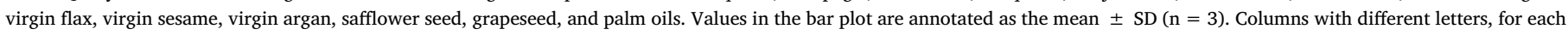
PhytoP, are significantly different at $p<0.05$ according to the ANOVA and Tukey's multiple range tests.

PhytoFs in tissues and organs, on their derivatives and esterified forms, and consequently on their potential biological interest. This should encourage the study of the bioavailability of PhytoPs and PhytoFs and their biological activity, essential to shed some light on the bioactive compound/s responsible for the contribution of plant foods to health and wellbeing in humans (Collado-González et al., 2017). However, to complete these studies, as a primary step, it is essential to select proper food matrices according not only to the plant oxylipins profile, but also the quantitative occurrence of such compounds.

The evaluation of the array of vegetable oils considered in the present work provided valuable information on the relative abundances of the separate PhytoPs and PhytoFs, and on their interest as dietary sources of such compounds. Hence, in the EVOOs the 9-series of $\mathrm{F}_{1^{-}}$-

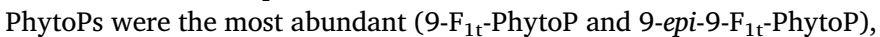
being found in concentrations ranging from 3.03 to $12.54 \mu \mathrm{gL}^{-1}$. On the other hand, in flax oil, besides the high concentration of the 9-series of $\mathrm{F}_{1}$-PhytoPs (14.02 and $10.56 \mu \mathrm{gL}^{-1}$, respectively), $\mathrm{D}_{1^{-}}, \mathrm{L}_{1^{-}}$, and $\mathrm{B}_{1^{-}}$PhytoPs were found at concentrations of up to 28.09, 28.67, and $19.22 \mu \mathrm{g} \mathrm{mL}^{-1}$, respectively (Fig. 2). The additional vegetable oils considered (argan, sesame, grapeseed, safflower, and palm) displayed amounts lower than the LOQ of the method - except for $9-\mathrm{F}_{1 \mathrm{t}}$-PhytoP, 16- $\mathrm{B}_{1}-\mathrm{Phyto} \mathrm{P}$, and $9-\mathrm{L}_{1}-\mathrm{Phyto}$, which were detected and quantified, although at much lower concentrations than in olive and flax oils $(0.54$, 0.25 , and $0.10 \mu \mathrm{g} \mathrm{m}^{-1}$, on average, respectively). Sesame and safflower oils also exhibited relatively high concentrations of ent-16- $\mathrm{F}_{1 \mathrm{t}^{-}}$ PhytoP and ent-16-epi- $\mathrm{F}_{1 \mathrm{t}}$-PhytoP (17.85 and $18.34 \mu \mathrm{gL}^{-1}$, respectively), which were at levels similar to those in flax oil (Fig. 2). These ranges of concentration are in agreement with those previously reported, with minor differences that could be attributable to the influence of the cultivar evaluated, the oil extraction technology, and/or storage conditions that make the oils prone to oxidation (Barbosa et al., 2015; Carrasco-del Amor et al., 2015; Carrasco-Del Amor et al., 2016; Carrasco-Del Amor et al., 2017; Collado-González, Moriana, et al., 2015; Karg et al., 2007).

Calculation of the total concentration of PhytoPs evidenced the preponderance of flax oil as a dietary source of these compounds with $119.15 \mu \mathrm{g} \mathrm{mL}^{-1}$, on average - a value that surpassed 7.3-fold the level found in the diverse varieties of EVOO $\left(16.31 \mu \mathrm{gL}^{-1}\right.$, on average $)$ and 6.1 -fold the levels in sesame and safflower oils $\left(19.42 \mu \mathrm{gL}^{-1}\right.$, on average). By contrast, PhytoPs were almost absent in argan, grapeseed, and palm oils, with values lower than $1.6 \%$ of that recorded in flax oil $\left(<1.90 \mu \mathrm{g} \mathrm{mL}^{-1}\right)$ (Fig. 2).
These values are partially in agreement with those of Karg et al. (2007), who described the concentrations of PhytoPs in edible oils (linseed, olive, soybean, rapeseed, and walnut), discriminating the classes $\mathrm{A}_{1^{-}}, \mathrm{B}_{1^{-}}, \mathrm{E}_{1^{-}}$, and $\mathrm{F}_{1^{-}}$PhytoPs. In this work of Karg et al., the $\mathrm{A}_{1^{-}}$, $\mathrm{B}_{1^{-}}, \mathrm{E}_{1^{-}}$, and $\mathrm{F}_{1}$-PhytoPs occurred in the concentration ranges 0.27-21.94 $\mu \mathrm{mol} \mathrm{L}^{-1} \quad\left(0.08-6.75 \mu \mathrm{g} \mathrm{m}^{-1}\right), \quad 0.07-7.77 \mu \mathrm{mol} \mathrm{L}^{-1}$ $\left(0.02-2.39 \mu \mathrm{g} \mathrm{mL}^{-1}\right), 3.41-66.50 \mu \mathrm{mol} \mathrm{L}^{-1}\left(1.11-21.7 \mu \mathrm{gL}^{-1}\right)$, and $0.45-33.54 \mu \mathrm{mol} \mathrm{L}^{-1}\left(0.35-11.00 \mu \mathrm{g} \mathrm{mL}^{-1}\right)$, respectively, with concentrations of total PhytoPs ranging from 7.31 to $81.16 \mu \mathrm{mol} \mathrm{L}^{-1}$ (2.38-26.43 $\mu \mathrm{g} \mathrm{mL}^{-1}$ ) (Karg et al., 2007). In addition, Karg et al. reported the relative preponderance of the F-, D-, and B-PhytoP classes; this depended not only on the type of matrix considered, but also on the features of the production procedures, which was further demonstrated by additional work in the field (Barbosa et al., 2015; Carrasco-del Amor et al., 2015; Karg et al., 2007).

The concentrations described by Karg et al. (2007) are lower than those obtained in the present work. Indeed, the concentration of total PhytoPs in our specific batch of olive oil samples $\left(16.31 \mu \mathrm{gL}^{-1}\right.$, on average) is 7-fold greater than that reported by Karg et al. These differences cannot be explained only by the analytical methodology applied; the genetic features of the cultivars evaluated, the agroclimatic conditions to which the olive tree crops are exposed, and the technological settings used to obtain the edible oils should be considered also (Carrasco-Del Amor et al., 2016; Carrasco-Del Amor et al., 2017; Collado-González et al., 2016; Collado-González, Moriana, et al., 2015; Collado-González, Pérez-López, et al., 2015; Imbusch \& Mueller, 2000a; Imbusch \& Mueller, 2000b; Karg et al., 2007; Sattler et al., 2006; Thoma, Krichke, Loeffler, \& Mueller, 2004). The impact of the technological settings on the final concentrations of PhytoPs and PhytoFs in vegetable oils is crucial to the selection of these food matrices for nutritional trials. In this sense, independently of the initial concentrations in foodstuffs, manufactured food needs to be further assessed.

The relative abundance of distinct PhytoPs classes cannot be compared among the diverse types of oils since it would be conditioned by specific physiological and molecular aspects; this would require equal matrices. For instance, flax oil has a preponderance of the 9-series of $\mathrm{D}_{1}$ - and $\mathrm{L}_{1}$-PhytoPs, whilst the olive oils, in agreement with Karg et al. (2007), show a dominance of the 9-series of $F_{1}$-PhytoPs. These differences, that could be due to the PUFAs profile of the separate matrices (since not all vegetable oils contain equal concentrations of ALA), should be taken into consideration when it is intended to study the specific biological activity of separate series of PhytoPs (Collado- 


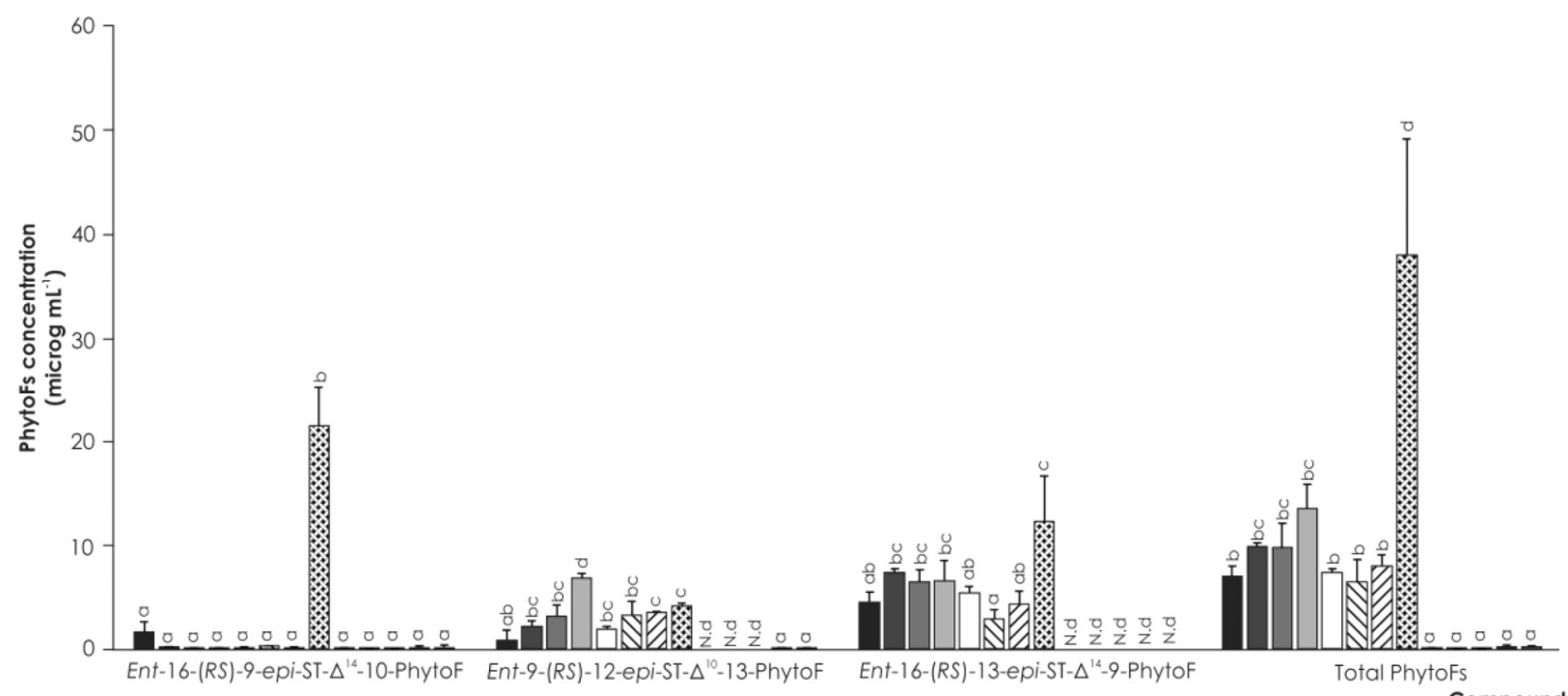

Compound

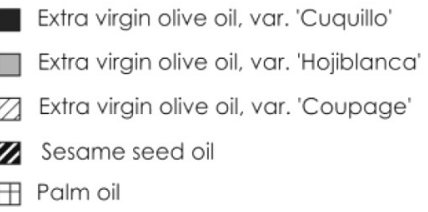

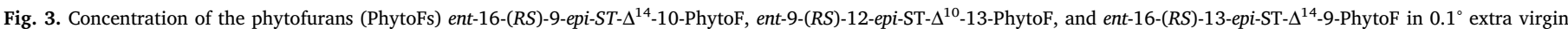

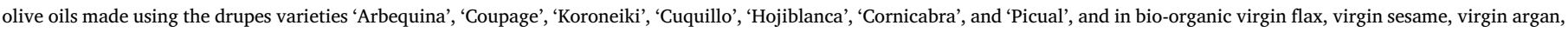

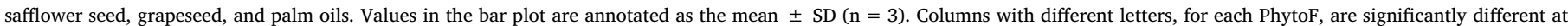
$p<0.05$ according to the ANOVA and Tukey's multiple range tests.

González, Moriana, et al., 2015). In this sense, it has been suggested that, under the physical conditions present during the olive oil production process, $16-\mathrm{B}_{1}-\mathrm{PhytoP}$ and $9-\mathrm{L}_{1}-\mathrm{PhytoP}$ could be released from the plant material into the covering liquid (Thoma et al., 2003).

To date, no information on the content of PhytoFs in vegetable oils has been reported. These compounds were detected in all 13 oils assessed in the present work, although with noteworthy differences among them. Thus, ent-16-(RS)-9-epi-ST- $\Delta^{14}-10$-PhytoF was the most abundant one in flax oil $\left(21.46 \mu \mathrm{gL}^{-1}\right.$, on average), surpassing the concentrations in the seven varieties of EVOO, as well as those in argan, sesame seed, grapeseed, safflower, and palm oils (which had similar, lower values), by $98.9 \%$, on average (Fig. 3). The concentration of Ent9-(RS)-12-epi-ST- $\Delta^{10}$-13-PhytoF was highest in EVOO var. 'Hojiblanca' $\left(6.87 \mu \mathrm{g} \mathrm{mL}^{-1}\right)$, with no significant differences between the remaining olive oils and flax oil $\left(2.72 \mu \mathrm{g} \mathrm{mL}{ }^{-1}\right.$, on average). Finally, with respect to ent-16-(RS)-13-epi-ST- $\Delta^{14}-9-$ PhytoF, flax oil again displayed the highest concentration $\left(12.28 \mu \mathrm{g} \mathrm{mL}^{-1}\right)$, although the statistical differences from the olive oils were dependent on the variety considered. Thus, whilst the concentrations in 'Cornicabra', 'Picual, and 'Hojiblanca' $\left(6.80 \mu \mathrm{gL}^{-1}\right.$, on average) did not differ significantly relative to flax oil ( $4.27 \mu \mathrm{g} \mathrm{mL}^{-1}$, on average), the concentrations in 'Cuquillo', Arbequina', 'Koroneiqui', and 'Coupage' were $65.2 \%$ (significantly) lower than in flax oil. Ent-16-(RS)-13-epi-ST- $\Delta^{14}$-9-PhytoF was not found in argan, sesame seed, grapeseed, safflower, or palm oil. The lowest concentration (or absence) of PhytoFs corresponded to argan, sesame seed, grapeseed, safflower, and palm oils (Fig. 3).

Similarly to PhytoPs, the highest concentration of total PhytoFs corresponded to flax oil $\left(37.92 \mu \mathrm{gL}^{-1}\right)$ and surpassed the concentration of the seven varieties of EVOO $\left(8.85 \mu \mathrm{g} \mathrm{mL} \mathrm{m}^{-1}\right.$, on average) by $76.7 \%$. The PhytoFs were almost absent in the remaining oils, that exhibited values ranging from 0.03 to $0.26 \mu \mathrm{gL}^{-1}$ (Fig. 3).

Although to date it has been initiated the study of the properties of vegetable oils as dietary sources of PhytoPs, as far as we know, only a few scientific articles have reported the occurrence of PhytoFs, plant metabolites derived from ALA oxidation induced by ROS and formed as a consequence of the addition of molecular oxygen after the initial cyclization of ALA in the biosynthesis of PhytoPs in nuts and seeds, as well as in melon leaves (Cuyamendous et al., 2015; Yonny et al., 2015). Nonetheless, PhytoFs have been identified in nuts, which are characterized by a high concentration of PUFAs. In this regard, Cuyamendous et al. described the presence of ent-16-(RS)-13-epi-ST- $\Delta^{14}-9$ PhytoF in concentrations that did not correlate significantly with that of ALA (Cuyamendous et al., 2015). Moreover, these compounds have been found also in vegetable oils of diverse origin, in different concentrations - reinforcing the relevance of the genetic background to the PhytoFs profile in higher plants (Carrasco-del Amor et al., 2015).

Independent of the individual compounds present in the separate foodstuffs, the evident higher concentrations of PhytoFs found in vegetable oils should be considered carefully because of the influence of the production processes on non-enzymatic oxidation of PUFAs and, consequently, on the final concentration of PhytoFs.

\subsection{Principal component analysis}

After profiling and quantifying the PhytoPs and PhytoFs in vegetable oils, the data were examined further using PCA, a statistical technique that simplifies a complex data set by reducing the number of variables (Anuar, Taha, \& Mahmad, 2015). This (theoretical) classification contributed to the identification of groups of vegetable oils according to their PhytoPs and PhytoFs profiles, thus indicating candidates for inclusion in future nutritional trials.

Hence, 12 components representing the total variance $(100.0 \%)$ were extracted, with the first nine explaining $>99.9 \%$ of the variance, whilst the first two principal components (PCs) explained $87.7 \%$ (Table 5). Concomitantly, the weight of each variable (chemical parameter) for the PCs was determined; the set of these loadings constitutes an Eigenvector (Wold, Esbensen, \& Geladi, 1987). Of the total variance, $70.2 \%$ was explained by PC1 (Table 5), being mostly attributable to 9- 
Table 5

Variance and cumulative variance provided by each principal component retrieved.

\begin{tabular}{lll}
\hline PC & Variance (\%) & Cumulative variance (\%) \\
\hline 1 & 70.2 & 70.2 \\
2 & 17.5 & 87.7 \\
3 & 5.7 & 93.4 \\
4 & 4.4 & 97.8 \\
5 & 1.2 & 98.9 \\
6 & 0.6 & 99.5 \\
7 & 0.4 & 99.9 \\
8 & 0.1 & $>99.9$ \\
9 & $<0.1$ & $>99.9$ \\
\hline
\end{tabular}

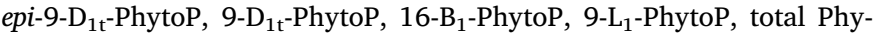
toPs, ent-16-(RS)-9-epi-ST- $\Delta^{14}-10-$ PhytoF, and total PhytoFs. With respect to PC2, the concentrations of 9- $\mathrm{F}_{1 \mathrm{t}^{-}}$PhytoP, ent-16-epi-16- $\mathrm{F}_{1 \mathrm{t}^{-}}$ PhytoP + ent-16- $\mathrm{F}_{1 \mathrm{t}}$-PhytoP, 9-epi-9- $\mathrm{F}_{1 \mathrm{t}}$-PhytoP, ent-9-(RS)-12-epi-ST$\Delta^{10}-13-P h y t o F$, and ent-16-(RS)-13-epi-ST- $\Delta^{14}-9$-PhytoF were the most relevant contributors. The percentage of the variance explained by PC2 was $17.5 \%$ (Table 5 ).

The PCA developed using the concentrations of PhytoPs and PhytoFs provided clusters alongside the PC1 vs PC2 plot (Fig. 4A). In this plot, the capacity of the PCA to discriminate the diverse matrices categorized according to the concentrations of these plant oxylipins was evident. Indeed, four clusters were clearly separated, with positive scores for PC1 (flax oil, -cluster 1-), negative scores for PC1 (argan, grapeseed, and palm oils -cluster 2- and sesame and safflower oils -cluster 3-), and intermediate (positive and negative) scores for PC1 (EVOOs, -cluster 4-). Regarding the ordinates axis (PC2), clusters 1-3 displayed positive scores, whilst cluster 4 had negative values.

The analysis of the samples distribution, jointly with the eigenvectors informing on the weight of each variable and the correlation between them, indicated the relationship of the observed classification with the abundance of compounds in the samples under evaluation. In this sense, the positive contribution of PhytoPs and PhytoFs to PC1 suggests a close correlation between the samples distribution and

A

Observations (axes PC1 and PC2: $87.7 \%$ )

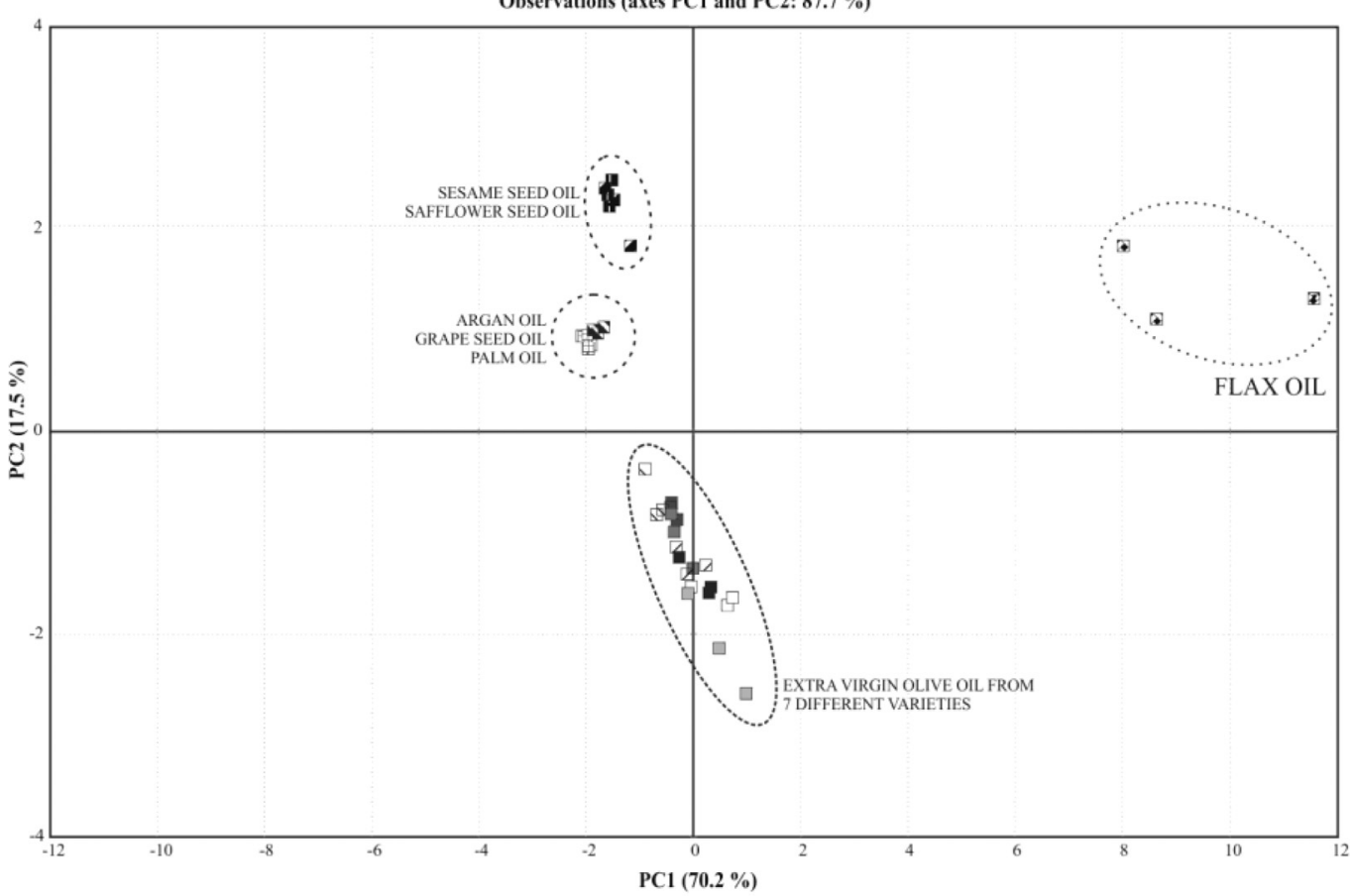

B

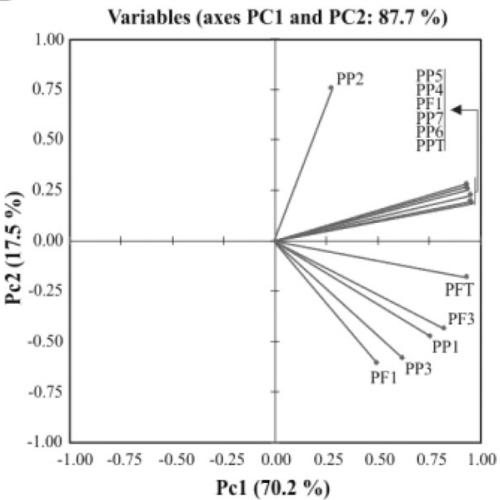

\begin{tabular}{|c|c|c|c|c|c|c|c|c|c|c|c|}
\hline Variables & PP1 & $\mathrm{PP} 2$ & PP3 & PP4 & PP5 & PP6 & PP7 & PPT & PF1 & $\mathrm{PF} 2$ & PF3 \\
\hline PP2 & $=0.023$ & & & & & & & & & & \\
\hline PP3 & $0.904^{* *}$ & -0.212 & & & & & & & & & \\
\hline PP4 & 0.561 & 0.392 & 0.409 & & & & & & & & \\
\hline PP5 & 0.547 & 0.404 & 0.404 & $0.989 * * *$ & & & & & & & \\
\hline PP6 & $0.628^{*}$ & 0.360 & 0.484 & $0.982^{* * *}$ & $0.982 * * *$ & & & & & & \\
\hline $\mathrm{PP} 7$ & $0.609^{*}$ & 0.376 & 0.460 & $0.994^{* * * 8}$ & $0.992^{* * *}$ & 0.996 & & & & & \\
\hline PPT & $0.704^{* *}$ & 0.470 & 0.562 & $0.954^{* * * *}$ & $0.959 * * *$ & 0.968 & $0.970^{* * *}$ & & & & \\
\hline PF1 & 0.576 & 0.388 & 0.450 & $0.993^{* * *}$ & $0.996 * * *$ & 0.982 & $0.993^{* * * *}$ & $0.965^{* * * *}$ & & & \\
\hline PF2 & 0.558 & -0.212 & 0.447 & 0.305 & 0.304 & 0.353 & 0.336 & 0.343 & 0.299 & & \\
\hline PF3 & $0.799^{* *}$ & -0.065 & $0.721^{* *}$ & $0.668^{\circ}$ & 0.653 & 0.707 & $0.698^{* *}$ & $0.712^{* * *}$ & $0.671^{*}$ & $0.718^{* *}$ & \\
\hline PFT & $0.748^{* *}$ & 0.135 & 0.627 & $0.847^{* * *}$ & $0.855^{* *}$ & $0-854$ & $0.864^{* * *}$ & $0.868^{* * *}$ & $0.861^{* * *}$ & $0.668^{*}$ & $0.912^{* * *}$ \\
\hline
\end{tabular}

The Pearson's coefficients indicate a significant correlation at $p<0.05\left({ }^{*}\right), p<0.01\left({ }^{* *}\right)$, and $p<0.001\left({ }^{* * *}\right)$.

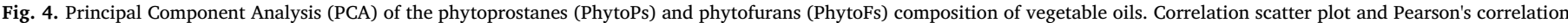

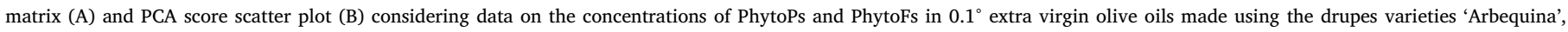

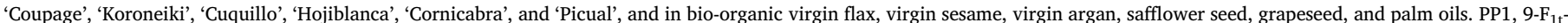

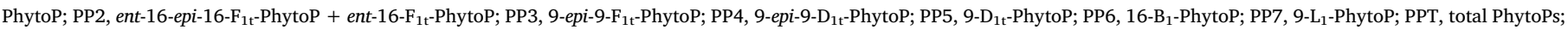
PF1, ent-16-(RS)-9-epi-ST- $\Delta^{14}-10-\mathrm{PhytoF}$; PF2, ent-9-(RS)-12-epi-ST- $\Delta^{10}-13$-PhytoF; PF3, ent-16-(RS)-13-epi-ST- $\Delta^{14}-9-\mathrm{PhytoF}$; PFT, total PhytoFs. 
clusters through the abscises axis, whilst the growing content of almost all individual PhytoPs and PhytoFs contributed to positive values along this axis (Fig. 4A and B). On the other hand, those variables contributing to PC2 negatively necessitate caution in the interpretation of the samples classification, since the vegetable oils achieving positive scores along the ordinate axis presented the lowest concentrations of the PhytoPs 9- $\mathrm{F}_{1 \mathrm{t}}$-PhytoP, ent-16-epi-16- $\mathrm{F}_{1 \mathrm{t}}-\mathrm{PhytoP}+$ ent- $16-\mathrm{F}_{1 \mathrm{t}}{ }^{-}$ PhytoP, and 9-epi-9- $\mathrm{F}_{1 \mathrm{t}}$-PhytoP and the PhytoFs ent-9-(RS)-12-epi-ST$\Delta^{10}$-13-PhytoF and ent-16-(RS)-13-epi-ST- $\Delta^{14}-9-\mathrm{PhytoF}$, and vice versa.

\section{Conclusions}

The recently emerging interest in the biological activity of vegetable oxylipins is related to their structural analogy with those of mammalian origin (isoprostanes and prostaglandins, among others), to which have been attributed a number of biological activities (still to be defined in detail) that make them relevant potential bioactive compounds at the physiological level. The selection of dietary sources of PhytoPs and PhytoFs is a major issue that needs to be addressed for the proper design of nutritional trials - that require the identification of a variety of foods, from among those widely included in the eastern dietary habits, as sources of these promising compounds. Thus, the joint analysis of the raw data and the results obtained from the PCA indicates that flax oil constitutes the best dietary source of PhytoPs and PhytoFs, whilst argan, grapeseed, and palm oils (all grouped in cluster 3 ) should be considered the most proper negative controls to be included in nutritional trials aimed at clarifying the actual bioavailability of such compounds given the virtual absence of PhytoPs and PhytoFs in their composition. In this respect, because of the negative connotations of the saturated fatty acids profiles of palm, argan, and grapeseed oils, these should be the options of choice. Moreover, this information may allow the selection of matrices to be incorporated into in vitro assays designed to yield mechanistic information on the biological activity of PhytoPs and PhytoFs in diverse pathophysiological situations. The demonstration of valuable biological activities for these compounds will boost, in the short term, the development of further studies on their capacity to act as functional analogs of mammalian oxylipins, contributing to the maintenance of the consumers' health and the development of a new family of functional products as a response to current health demands.

\section{Acknowledgements}

This work was partially funded by the "Fundación Séneca de la Región de Murcia" Grupo de Excelencia 19900/GERM/15. RDP was supported by a Postdoctoral Contract (Saavedra-Fajardo 20024/SF/16) from the Agency for Science and Technology of the Región de Murcia (Spain). This work is included in the framework of the collaboration between the Spanish Research Council (CEBAS-CSIC) and CNRSUniversity of Montpellier as "Projets Internationaux de Cooperation Scientifique (PICS-2015-261141). We are grateful to Dr. David Walker (native English speaker) for his review of the English grammar and style of the current report.

\section{References}

Anuar, N., Taha, R. M., \& Mahmad, N. (2015). Correlation of colour, antioxidant capacity, and phytochemical diversity of imported saffron by principal component analysis. Pigment \& Resin Technology, 46, 107-114.

Barbosa, M., Collado-González, J., Andrade, P. B., Ferreres, F., Valentão, P., Galano, J. M., Gil-Izquierdo, A. (2015). Nonenzymatic $\alpha$-Linolenic acid derivatives from the sea: Macroalgae as novel sources of phytoprostanes. Journal of Agricultural and Food Chemistry, 63, 6466-6474.

Barden, A., Mas, E., Henry, P., Durand, T., Galano, J. M., Roberts, L. J., ... Mori, T. A. (2011). The effects of oxidation products of arachidonic acid and $\mathrm{n} 3$ fatty acids on vascular and platelet function. Free Radical Research, 45, 469-476.

Barden, A. E., Croft, K. D., Durand, T., Guy, A., Mueller, M. J., \& Mori, T. A. (2009). Flaxseed oil supplementation increases plasma F1phytoprostanes in healthy men. Journal of Nutrition, 139, $1890-1895$.

Carrasco-Del Amor, A. M., Aguayo, E., Collado-Gonzalez, J., Guy, A., Galano, J. M.,
Durand, T., \& Gil-Izquierdo, A. (2016). Impact of packaging atmosphere, storage and processing conditions on the generation of plant oxidative stress markers in almond kernels: Phytoprostanes. Food Chemistry, 211, 869-875.

Carrasco-Del Amor, A. M., Aguayo, E., Collado-Gonzalez, J., Guy, A., Galano, J. M., Durand, T., \& Gil-Izquierdo, A. (2017). Impact of processing conditions on the phytoprostanes profile of three types of nut kernels. Free Radical Research, 51, 141-147.

Carrasco-del Amor, A. M., Collado-González, E., Aguayo, E., Guy, A., Galano, J. M., Durand, T., \& Gil-Izquierdo, A. (2015). Phytoprostanes in almonds: Identification, quantification, and impact of cultivar and type of cultivation. RSC Advances, 5, 51233-51241.

Collado-González, J., Grosso, C., Valentão, P., Andrade, P. B., Ferreres, F., Durand, T., .. Gil-Izquierdo, A. (2017). Inhibition of a-glucosidase and a-amylase by Spanish extra virgin olive oils: The involvement of bioactive compounds other than oleuropein and hydroxytyrosol. Food Chemistry, 235, 298-307.

Collado-González, J., Medina, S., Durand, T., Guy, A., Galano, J. M., Torrecillas, A., ... GilIzquierdo, A. (2015). New UHPLCQqQ-MS/MS method for quantitative and qualitative determination of free phytoprostanes in foodstuffs of commercial olive and sunflower oils. Food Chemistry, 178, 212-220.

Collado-González, J., Moriana, M., Girón, I. F., Corell, M., Medina, S., Durand, T., ... GilIzquierdo, A. (2015). The phytoprostane content in green table olives is influenced by Spanish-style processing and regulated deficit irrigation. LWT-Food Science \& Technology, 64, 997-1003.

Collado-González, J., Pérez-López, D., Houssem, M., Gijón, M. C., Medina, S., Durand, T. Gil-Izquierdo, A. (2016). Effect of the season on the free phytoprostane content in Cornicabra extra virgin olive oil from deficit-irrigated olive trees. Journal of the Science of Food and Agriculture, 96, 1585-1592.

Collado-González, J., Pérez-López, D., Memmi, H., Gijón, M. C., Medina, S., Durand, T.,... Gil-Izquierdo, A. (2015). Water deficit during pit hardening enhances phytoprostanes content, a plant biomarker of oxidative stress, in extra virgin olive oil. Journal of Agricultural and Food Chemistry, 63, 3784-3792.

Commission Decision 2002/657/EC (12 August 2002). Implementing Council Directive 96/23/EC concerning the performance of analytical methods and the interpretation of results. Official Journal of the European communities, 221, 8-36 (L221-8 17.8.2002).

Cuyamendous, C., de la Torre, A., Lee, Y. Y., Leung, K. S., Guy, A., Bultel-Poncé, V., ... Durand, T. (2016). The novelty of phytofurans, isofurans, dihomo-isofurans and neurofurans: Discovery, synthesis and potential application. Biochimie, 130, 49-62.

Cuyamendous, C., Leung, K. S., Bultel-Poncé, V., Guy, A., Durand, T., Galano, J. M., ... Oger, C. (2017). Total synthesis and in vivo quantitation of phytofurans derived from a-linolenic acid. European Journal of Organic Chemistry, 2017(17), 2486-2490.

Cuyamendous, C., Leung, K. S., Durand, T., Lee, J. C. Y., Oger, C., \& Galano, J. M. (2015). Synthesis and discovery of phytofurans: Metabolites of $\alpha$-linolenic acid peroxidation. Chemical Communications, 51, 15696-15699.

de la Torre, A., Lee, Y. Y., Mazzoni, A., Guy, A., Bultel-Poncé, V., Durand, T., ... Galano, J. M. (2015). Total syntheses and in vivo quantitation of novel neurofuran and dihomoisofuran derived from docosahexaenoic acid and adrenic acid. Chemistry, 21(6), 2442-2446.

Dupuy, A., Le Faouder, P., Vigor, C., Oger, C., Galano, J. M., Dray, C., ... Bertrand-Michel, J. (2016). Simultaneous quantitative profiling of 20 isoprostanoids from omega- 3 and omega-6 polyunsaturated fatty acids by LC-MS/MS ibn various biological samples. Analytica Chimica Acta, 921, 46-58.

El Fangour, S., Guy, A., Despres, V., Vidal, J. P., Rossi, J. C., \& Durand, T. (2004). Total syntheses of the eight diastereoisomers of the syn-anti-syn phytoprostanes F1 types I and II. The Journal of Organic Chemistry, 69(7), 2498-2503.

El Fangour, S., Guy, A., Vidal, J. P., Rossi, J. C., \& Durand, T. (2005). A flexible synthesis of the phytoprostanes B1 type I and II. The Journal of Organic Chemistry, 70(3), 989-997.

FDA, US Department of Health and Human Services (May, 2001). Guidance for industry: bioanalytical method validation. Available: http://www.fda.gov/cder/guidance.

Fessel, J. P., Porter, N. A., Moore, K. P., \& Sheller, J. R. (2002). Discovery of lipid peroxidation products formed in vivo with a substituted tetrahydrofuran ring (isofurans) that are favored by increased oxygen tension. Proceedings of the National Academy of Sciences, 99, 16713-16718.

Guy, A., Flanagan, S., Durand, T., Oger, C., \& Galano, J. M. (2015). Facile synthesis of cyclopentenone B1- and $\mathrm{L}_{1}$ - type phytoprostanes. Frontiers in Chemistry, 3, 41.

Imbusch, R., \& Mueller, M. J. (2000a). Analysis of oxidative stress and wound-inducible dinor isoprostanes $\mathrm{F}_{1}$ (phytoprostanes $\mathrm{F}_{1}$ ) in plants. Plant Physiology, 124 1293-1303.

Imbusch, R., \& Mueller, M. J. (2000b). Formation of isoprostane F(2).like compounds (phytoprostanes F(1)) from alpha-linolenic acid in plants. Free Radicals Biology \& Medicine, 28(5), 720-726.

International Conference on Harmonization (ICH) (1994). Validation of analytical method: Definitions and terminology. ICH Q2A, Geneva.

Jahn, U., Galano, J. M., \& Durand, T. A. (2010). A cautionary note on the correct structure assignment of phytoprostanes and the emergence of a new prostane ring system. Prostaglandins, Leukotrienes, \& Essential Fatty Acids, 82, $83-86$.

Karg, K., Dirsch, V. M., Vollmar, A. M., Cracowski, J. L., Laporte, F., \& Mueller, M. J. (2007). Biologically active oxidized lipids (phytoprostanes) in the plant diet and parenteral lipid nutrition. Free Radical Research, 41(1), 25-37.

Leung, K. S., Chen, X., Zhong, W., Yu, A. C. H., \& Lee, C. Y. J. (2014). Microbubblemediated sonoporation amplified lipid peroxidation of Jurkat cells. Chemistry and Physics of Lipids, 180, $53-60$.

Loeffler, C., Berger, S., Guy, A., Durand, T., Bringmann, G., Dreyer, M., ... Mueller, M. (2005). $B_{1}$-phytoprostanes trigger plant defense and detoxification responses. Plant Physiology, 137, 328-340.

Medina, S., Dominguez-Perles, R., Gil, J. I., Ferreres, F., Garcia Viguera, C., Martínez- 
Sanz, J. M., \& Gil-Izquierdo, A. (2012). A ultra-pressure liquid chromatography/triple quadrupole tandem mass spectrometry method for the analysis of 13 eicosanoids in human urine and quantitative 24 hour values in healthy volunteers in a controlled constant diet. Rapid Communications in Mass Spectrometry, 26(10), 1249-1257.

Mueller, N. J. (2004). Archetype signals in plants: The phytoprostanes. Current Opinion in Plant Biology, 7(4), 32650-32655.

Oger, C., Brinkmann, Y., Bouazzaoui, S., Durand, T., \& Galano, J. M. (2008). Stereocontrolled access to isoprostanes via a bicyclo[3.3.0] octene framework. Organic Letters, 10, 5087-5090.

Pinot, E., Guy, A., Fournial, A., Balas, L., Rossi, J. C., \& Durand, T. (2008). Total synthesis of the four enantiomerically pure diasteroisomers of the phytoprostanes E1Type II and of the 15- $\mathrm{E}_{2 \mathrm{t}}$-isoprostanes. Journal of Organic Chemistry, 73(8), 3063-3069.

Roberts, L. J., 2nd, \& Fessel, J. P. (2004). The biochemistry of the isoprostane, neuroprostane, and isofuran pathways of lipid peroxidation. Chemistry and Physics of Lipids, 128(1-2), 173-186.

Sattler, S. E., Méne Saffrané, L., Farmer, E. E., Krichke, M., Mueller, M. J., \& DellaPenna, D. (2006). Nonenzymatic lipid peroxidation reprograms gene expression and activates defense markers in Arabidopsis tocopherol-deficient mutants. Plant Cell, 18(12), 3706-3720.

Taber, D. F., Morrow, J. D., \& Roberts, L. J., 2nd (1997). A nomenclature system for the isoprostanes. Prostaglandins, 53(2), 63-67.

Thoma, I., Krichke, M., Loeffler, C., \& Mueller, M. J. (2004). The isoprostanoid pathway in plants. Chemistry and Physics of Lipids, 12881(2), 135-148.

Thoma, I., Loeffler, C., Sinha, A., Gupta, M., Krichke, M., Stephan, B., ... Mueller, M. J. (2003). Cyclopentanone isoprostanes induced by reactive oxygen species trigger defense gene activation and phytoalexin accumulation in plants. Plant Journal, 34, 363-375.

Wold, S., Esbensen, K., \& Geladi, P. (1987). Principal component analysis. Chemometric and Intelligent Laboratory Systems, 2, 37-52.

Yonny, M. E., Rodríguez-Torresi, A., Cuyamendous, C., Réversat, G., Oger, C., Galano, J. M., ... Nazareno, M. A. (2015). Thermal stress in melon plants: Phytoprostanes and phytofurans as oxidative stress biomarkers and the effect of antioxidant supplementation. Journal of Agricultural and Food Chemistry, 64, 8296-8304. 